\title{
FORMAÇÃO E COMPETÊNCIA INFORMACIONAL DO BIBLIOTECÁRIO MÉDICO BRASILEIRO
}

Alexander Willian Azevedo
Vera Silvia Marão Beraquet

\section{Resumo:}

Esta pesquisa teve como objetivo investigar as diferentes abordagens acerca da formação dos bibliotecários-médicos, a fim de observar suas características e propostas, e identificar as competências informacionais que seriam desejáveis a este profissional no Brasil. Considerando que a prática da Biblioteconomia Médica é recente no Brasil, o método utilizado para alcançar os objetivos propostos foi desenvolvido por meio de revisão de literatura de textos extraídos em bases de dados nacionais e internacionais, e valeu-se do caráter qualitativo por ser pesquisa bibliográfica de natureza exploratória que proporcionou observamos os conceitos, formação e as principais competências informacionais presentes nos bibliotecários-médicos. Os principais resultados obtidos indicam que: as escolas de Biblioteconomia no Brasil passaram por diversas reformulações em suas grades curriculares, visando capacitar os bibliotecários a terem iniciativas, motivações, pró-atividade e ser receptivo às mudanças, para atuar em várias áreas do conhecimento, inclusive na área médica. Os resultados também evidenciaram que as principais habilidades e atitudes inerentes aos bibliotecários médicos brasileiros, não diferem do perfil dos bibliotecários generalistas, no sentido de terem competências para atuarem em bibliotecas especializadas.

\section{Palavras-chave:}

Competência informacional; Biblioteconomia médica; Bibliotecário médico; Formação do Bibliotecário médico

\section{TRAINING AND INFORMATION LITERACY OF BRAZILIAN MEDICAL LIBRARIAN}

\begin{abstract}
:
This study aimed to investigate the different approaches on the training of medical librarians, in order to observe their characteristics and proposals, and to identify the information literacy that would be desirable to these professionals in Brazil. Whereas the practice of the Medical Librarianship is recent in Brazil, the method used to achieve the proposed objectives has been developed through literature review of texts extracted from national and international databases It also took advantage of its qualitative character, due to the fact of being bibliographical research of self exploratory nature, which made possible to observe the main skills and information literacy of medical librarians. The main results of the research indicate that librarianship schools in Brazil went through several reformulations in their curricula, to enable librarians to take initiatives, have motivation, proactive attitudes and to be receptive to changes, in order to act in several areas of knowledge, including medical field. The results also demonstrated that the main characteristics of Brazilian medical librarians do not differ from the general profile of librarians, meaning that they should not have special skills to work in specialized libraries.
\end{abstract}

\section{Keywords:}

Information literacy; Medical librarianship; Medical librarian; Medical librarian training 


\section{Introdução}

Os estudos sobre as competências necessárias de uma atividade são comuns em trabalhos de graduação e pós-graduação das diversas áreas do conhecimento, assim como na Biblioteconomia e Ciência da Informação. Freqüentemente são colocadas em questão a formação dos bibliotecários por conta das diversas transformações ocorridas na sociedade e na evolução das tecnologias.

Atualmente se observa que os usuários de informação adquiriram habilidades informacionais que exigem dos bibliotecários uma participação ativa em todo o processo de busca, avaliação e uso da informação, conduzindo, desta forma, que os bibliotecários abandonem a postura de isolamento, de modo que possam interagir eficazmente diante da capacitação constante dos usuários de informação.

Desta forma, ciente da dimensão do espaço de atuação aberto para os bibliotecários, este estudo tem como proposta de analisar a realidade que demanda um bibliotecário médico, na sua formação e suas competências informacionais de modo a estar apto para lidar com a informação da área médica, e com os usuários especializados que demanda esta área.

A discussão em torno da competência informacional no campo da Biblioteconomia ganhou significativo destaque desde a década 1980, principalmente nos EUA, com a publicação do documento da American Library Association (ALA) intitulado: Libraries and the Learning Society: Papers in Response to A Nation at Risk, que apresentava a importância do papel da biblioteca no processo de aprendizagem de habilidades que ensinasse o usuário a buscar e usar informação (ALA, 2003).

No cenário brasileiro, a inclusão dos estudos sobre a competência informacional na Biblioteconomia e na Ciência da Informação, repercutiu a partir dos estudos de Carenagto (2000), Belluzzo, (2001); Hatschbach (2002); Campello (2003) e Dudziak, (2003) que apresentam em suas pesquisas as questões sobre os conceitos da competência informacional e sua aplicabilidade como função pedagógica na educação dos usuários da informação. 
Neste contexto, utilizaremos como definição para expressão competência informacional a referência ao conjunto de habilidades e atitudes de "[...] localizar, avaliar e usar efetivamente a informação” (ALA, 2003), que leva a abranger desde a organização e uso da informação à expansão de habilidades para um processo de tomada de decisão na vida social, profissional, acadêmica, entre outros.

Com base nesta definição, constitui-se a preocupação em torno da formação dos bibliotecários médicos e suas competências informacionais para atuar diretamente como um mediador junto aos usuários, sejam estes médicos, docentes, discentes, residentes, pacientes, entre outros usuários de informação. Segundo Kajberg e Lorring (2005), os bibliotecários têm a função especifica de aplicar os conceitos teóricos da competência informacional na prática, visando facilitar o acesso à informação e ajudar os usuários a satisfazerem suas necessidades informacionais.

Nesta questão é que se insere o problema deste estudo, pois o fato de já existir a prática da Biblioteconomia Médica no Brasil e de publicações de artigos e dissertações que evidenciam esta prática biblioteconômica, conforme relatadas em pesquisas com Crestana (2003); Pinto (2005), Pereira (2005), Martinez-Silveira (2005); Galvão e Leite (2008), indica a necessidade de se analisar a formação e as competências dos bibliotecários médicos no Brasil.

Portanto, este estudo foi desenvolvido por meio de revisão de literatura de textos extraídos em bases de dados nacionais e internacionais que teve como objetivo geral explicitar as diferentes abordagens acerca da formação dos bibliotecários médicos, suas características e propostas, bem como as competências informacionais delineadas para este profissional no Brasil. Foram estabelecidos como objetivos específicos: (a) analisar os conceitos e contextos relacionados aos bibliotecários médicos; e (b) caracterizar a formação dos bibliotecários médicos na literatura nacional e estrangeira.

\section{Profissionais da Informação}

A expressão profissional da informação estabelece em sua definição referência com aqueles que trabalham diretamente com a informação, tendo este como seu objeto de trabalho. De forma genérica, a expressão profissional da informação pode designar

(c) Revista Digital de Biblioteconomia e Ciência da Informação,Campinas, v.7, n. 2, p. 199-218, jan.jjun. 2010- ISSN: 1678-765X. 
aqueles que atuam no campo da Biblioteconomia e Ciência da Informação como também em outras áreas da comunicação (ALMEIDA JR, 2002).

Os profissionais da informação bibliotecários fora do contexto brasileiro, especialmente nos EUA e no Reino Unido, tiveram em seu processo de consolidação, desde a graduação até reconhecimento da profissão, fortemente influenciado pelas associações que os representavam, conforme relata Kramer (1972) que resgata, em sua pesquisa, a importância da representação da classe dos bibliotecários por uma associação, como American Library Association (ALA) nos EUA.

Um ponto importante a ser destacado no estudo da autora é que a ALA, desde sua fundação, esteve ligada às políticas e às ações vigentes no EUA, visando desta forma transmitir ao governo as opiniões e projetos da categoria do profissional da informação bibliotecário. Neste intuito, Melvin Dewey, que foi o primeiro secretário e mentor da ALA, fundou em 1887, a primeira escola superior de Biblioteconomia na Universidade de Columbia nos EUA, encerrando a rotina de treinamentos que até então predominava nas bibliotecas dos EUA (KRAMER, 1972).

Observa-se que, no Brasil, diferentemente do caso dos nortes americanos, as escolas de Biblioteconomia tiveram influência em todo processo de consolidação tanto da profissão de bibliotecário, como na estruturação dos currículos acadêmicos.

De acordo com as diretrizes curriculares para os cursos de Biblioteconomia no Brasil aprovadas em abril de 2001 pelo Conselho Nacional de Educação (Brasil, 2002) e elaboradas pela Comissão de Especialistas da área de Ciência da Informação, nomeada pela Secretaria de Ensino Superior do Ministério de Educação, o profissional da informação bibliotecário deve “[...] enfrentar com proficiência e criatividade os problemas de sua prática profissional, produzir e difundir conhecimentos, refletir criticamente sobre a realidade que o envolve, buscar aprimoramento contínuo, observar padrões éticos de conduta (BRASIL, 2001; ASSOCIAÇÃO BRASILEIRA DE EDUCAÇÃO EM CIÊNCIA DA INFORMAÇÃO, 2000).

No estudo realizado por Ferreira (2003), sobre o perfil de habilidades do profissional da informação demandadas pelo mercado de trabalho, constatou-se que o papel do 
profissional da informação é o de assistir, intermediar e apoiar outras pessoas na busca de informações, por meio da gestão da informação, e que a evolução das TIC, dos suportes e produtos informacionais demandam modificações às exigências de atuação, formação e capacitação do profissional da informação.

Mediante este fato, observa-se que nas bibliotecas especializadas, como as bibliotecas médicas, exigem dos bibliotecários, em sua prática, necessidade de se capacitarem constantemente para atender às necessidades informacionais da comunidade/usuário com que estejam envolvidos.

Para Crestana (2003, p.136), os bibliotecários que já atuam nas bibliotecas médicas, pertencem ao grupo de trabalhadores denominados de profissionais da informação em saúde, uma vez que suas ocupações estão vinculadas às atividades de “[...] ensino e pesquisa dos profissionais de saúde, e por escolha profissional, desempenham suas atividades na área da Ciência Médica”.

Neste sentido, por força da demanda de atuações da prática biblioteconômica, os bibliotecários acabaram se envolvendo cada vez mais com a especialização e /ou com ênfase em uma área especifica.

\section{Bibliotecário Médico}

No final do século XX, área da saúde apresentava-se inundada por fontes, produtos e serviços de informação, vendo-se os bibliotecários e usuários de informação envolvidos por uma rápida mudança tecnológica e por múltiplas fontes e formas de pesquisa. Considerando que o conhecimento médico registrado tende a crescer exponencialmente, acompanhado pelo desenvolvimento das TIC, o que afeta em vários aspectos a rotina do trabalho médico, foram geradas novas oportunidades para bibliotecários que atuam em bibliotecas médicas, no auxilio para sanar as necessidades informacionais dos médicos (MEDICAL LIBRARY ASSOCIATION, 1992).

Diante desta nova oportunidade estão implicados os bibliotecários médicos, que se trata dos bibliotecários atuantes em bibliotecas das Faculdades de Medicina. Estes profissionais colaboram com os profissionais da saúde, e, segundo Crestana (2003), 
podem cooperar no diagnóstico médico, realizam atividades de buscas de informações em saúde para os discentes, docentes e pesquisadores na área da Medicina, disseminam informações sobre saúde e uso de diferentes canais de comunicação, como o de bases de dados especializados.

Em resposta ao acúmulo de informação cientifica na área médica em confronto a prática da Biblioteconomia Médica, a MLA publicou, em 1992, o documento titulado: Platform for Change. The Educational Policy Statement of the Medical Library Association (Plataforma para a Mudança: A Declaração de Política Educacional da Associação das Bibliotecas Médicas), visando fornecer uma agenda de ações detalhadas das competências dos bibliotecários médicos, bem como fornecer orientações sobre a necessidade da educação continuada que envolve esta prática.

Em complemento ao documento citado, a NLM publica em 1995: The Education and Trainning of Health Sciences Librarians (Educação e Treinamento para Bibliotecários em Ciências da Saúde) para certificar-se de que a sociedade seja beneficiada com as competencias dos bibliotecários que tem suas atividades com ênfase na área da saúde, frisando a necessidade destes profissionais com relação à educação continuada (ANNAN, 1998).

A prática da Biblioteconomia Médica teve sua origem no EUA, destacou-se pelas iniciativas na formação de bibliotecários médicos, que, desde 1898, promovem encontros anuais destes profissionais através de sua associação: Medical Library Association (MLA); isto contribuiu para que, em 1948, iniciasse o primeiro curso para bibliotecários médicos, aplicado no programa oferecido na Columbia University School of Library Service (BELL, 1996 e SCHACHER, 2001).

Na década de 1990, com o início da prática da Medicina Baseada em Evidência (MBE), nos currículos dos cursos de Medicina nos EUA, Canadá e em países europeus, os bibliotecários que atuavam nas bibliotecas médicas ganhou maior destaque e evidência em torno do processo de busca, seleção e avaliação crítica da literatura para responder a questões que permeiam o conceito de MBE (ATALLAH e CASTRO, 1998). 
A Medicina Baseada em Evidência (MBE), expressão cunhada na Mcmaster Medical School, no Canadá, para designar o processo de sistematicamente descobrir, avaliar e utilizar achados de pesquisas recentes, como bases para decisões clínicas, é composta, segundo Rosenberg e Donald (1995, p.125) por quatro características básicas: “1º formular uma questão clínica clara a partir de um problema do paciente; $2^{\circ}$ pesquisar na literatura os artigos relevantes; $3^{\circ}$ avaliar a evidência de sua validade e utilização; e $4^{\circ}$ implementar o uso deste achado na prática clínica”.

4 Formação dos bibliotecários no Brasil: da formação generalista para a ênfase na área da informação em saúde.

A formação do bibliotecário no Brasil contou com duas experiências no campo da educação, inicialmente com a escola humanista européia e depois sob a influência da escola tecnicista norte-americana, segundo Valentim (2002) tais escolas foram os alicerces da constituição dos bibliotecários atuais, que tem suas habilidades adquirida da graduação.

Na observação de Valentim (2002), independentemente da escola de formação dos bibliotecários, existem pontos consensuais nas propostas do profissional bibliotecário, ou seja, quanto ao domínio de competências informacionais. Segundo a mesma autora, as competências necessárias para a formação do bibliotecário tendem a estar em consonância com o conjunto de habilidades, destrezas, atitudes e conhecimentos teóricospráticos necessitados para cumprir uma função especializada e garantir resultado satisfatório de seu trabalho tanto para seus usuários para a comunidade na qual faz parte.

A discussão em torno da formação do bibliotecário brasileiro, proposta pelas Diretrizes Curriculares para os Cursos de Biblioteconomia do Brasil no Parecer CNE/CES n ${ }^{\circ}$ 492/2001 (BRASIL, 2001), sugere dois grupos de competências a serem asseguradas na formação acadêmica do bibliotecário:

Gerais

- Gerar produtos a partir dos conhecimentos adquiridos e divulgá-los;

- Formular e executar políticas institucionais;

- Elaborar, coordenar, executar e avaliar planos, programas e projetos;

- Utilizar racionalmente os recursos disponíveis; 
- Desenvolver e utilizar novas tecnologias;

- Traduzir as necessidades de indivíduos, grupos e comunidades nas respectivas áreas de atuação;

- Desenvolver atividades profissionais autônomas, de modo a orientar, dirigir, assessorar, prestar consultoria, realizar perícias e emitir laudos técnicos e pareceres;

- Responder a demandas sociais de informação produzidas pelas transformações tecnológicas que caracterizam o mundo contemporâneo.

\section{Específicas}

- Interagir e agregar valor nos processos de geração, transferência e uso da informação, em todo e qualquer ambiente;

- Criticar, investigar, propor, planejar, executar e avaliar recursos e produtos de informação;

- Trabalhar com fontes de informação de qualquer natureza;

- Processar a informação registrada em diferentes tipos de suporte, mediante a aplicação de conhecimentos teóricos e práticos de coleta, processamento, armazenamento e difusão da informação;

- Realizar pesquisas relativas a produtos, processamento, transferência e uso da informação.

Estas diretrizes enfatizam que as competências enumeradas são determinantes para a reflexão sobre formação e avaliação do próprio profissional da informação, levando à consideração de que a educação continuada é fundamental para o profissional da informação poder consolidar sua competência.

No campo da Biblioteconomia Médica no Brasil, o enfoque de formação do profissional da informação em saúde, ou seja, bibliotecário médico ainda é algo recente. Segundo Galvão e Leite (2008), a graduação em Biblioteconomia, Documentação e CI no Brasil, priorizam uma formação de um profissional generalista e não tematizada.

Uma iniciativa que vem se destacando no cenário nacional é a proposta do curso de Ciência da Informação e da Documentação da Universidade de São Paulo (USP), campus de Ribeirão Preto, cuja graduação em CI apresenta ênfase em informação em saúde. (GALVÃO e LEITE, 2008).

\section{O bibliotecário como mediador entre a informação e usuário}


No passado, os profissionais de saúde não tinham de lidar com o volume de informações atualmente disponível no ambiente médico. O paciente ficava, anteriormente, restrito às informações dadas pelo médico; no presente, têm inúmeras oportunidades de acesso a fontes de conhecimento científico, através da mídia, bibliotecas médicas, associações e principalmente pela internet (NAKAYAMA, 2004).

Vista esta situação, os bibliotecários médicos adquiriram maior espaço de interatividade com seus usuários, principalmente os médicos, pois, com a habilidade de comunicação e acesso à informação em saúde pelos usuários, os médicos viram-se diante da necessidade de atualização de seus conhecimentos para tomada de decisão em seu diagnóstico.

Embora as mudanças ocorridas no ambiente da Medicina, como autonomia dos pacientes na busca de informação e a necessidade constante de atualização por parte dos médicos, tem-se apresentado evidências da importância dos profissionais da informação em saúde nos seus conhecimentos e competências (MEDICAL LIBRARY ASSOCIATION, 1992). Esses profissionais da informação em saúde podem ser denominados como bibliotecários médicos, bibliotecários clínicos e informacionistas clínicos.

Portanto, os profissionais da informação em saúde inserem-se nas observações de Ortega y Gasset (1935), que imaginava futuro do bibliotecário como um filtro entre os livros e o homem, algo que pode ser encontrado contemporaneamente na prática da Biblioteconomia.

Estes profissionais assemelham-se na busca das melhores evidências científicas para um tratamento médico, situações em que os profissionais da informação em saúde têm a função de atuarem em colaboração com todo o processo informacional, como representado na figura 1 abaixo:

(c) Revista Digital de Biblioteconomia e Ciência da Informação,Campinas, v.7, n. 2, p. 199-218, jan./jun. 2010- ISSN: 1678-765X. 


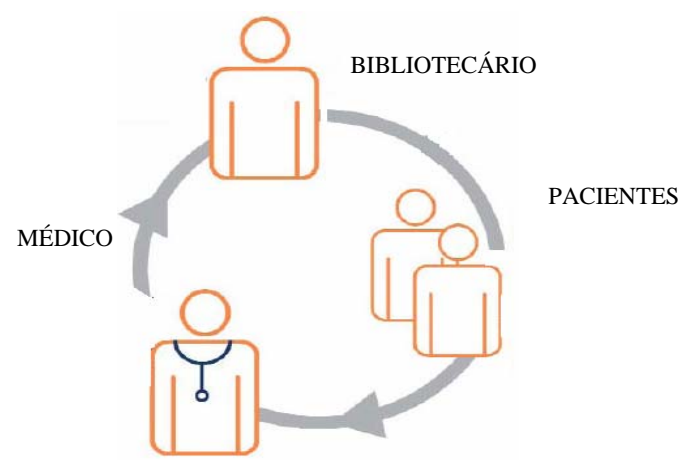

Figura 1 - Médico, paciente e bibliotecário: mediação da informação.

Portanto, a figura acima ilustra o desenvolvimento do trabalho em colaboração entre médico, paciente e o bibliotecário, o que pode contribuir de maneira significativa para o acesso imediato à evidência científica, beneficiando diretamente os pacientes.

É inegável a contribuição e a importância dos bibliotecários que atuam em bibliotecas das Faculdades de Medicina. Entretanto, a Biblioteconomia e a Ciência da Informação devem acompanhar e subsidiar as possibilidades de evolução que culminam novas necessidades informacionais, principalmente na área da informação em saúde.

\section{Resultados}

Durante a análise dos dados, foi verificado que tópicos pertinentes à formação do bibliotecário brasileiro mostrou-se relevante, uma vez que esta discussão é determinante em muitos aspectos relacionados com a atuação do bibliotecário, pois, ainda que este profissional venha a se especializar em outras áreas do conhecimento, sua formação na graduação em Biblioteconomia e/ou Ciência da Informação certamente será a base constitutiva de suas competências informacionais requeridas para realizar suas atividades.

É fato que, foi constatado que desde a época da regulamentação da profissão de bibliotecário, as escolas de Biblioteconomia já ofereciam um ensino voltado para o domínio de técnicas biblioteconômicas para atuar em diferentes especialidades. 
Diante do exposto, pode-se notar que o bibliotecário brasileiro encontra-se em um momento em que lhe são expostos novos espaços de atuação, a partir de sua formação generalista.

Neste cenário apresentado, pontuado pelas reformulações curriculares nos cursos de Biblioteconomia, que se refletem as evoluções das TIC e das novas demandas de mercado de trabalho do bibliotecário. Este profissional, no exercício de suas atividades, geralmente quando atuando em bibliotecas especializadas, se vê diante de um novo campo de conhecimento, situação da qual decorre a questão acerca da educação.

Analisando a literatura sobre a formação dos bibliotecários brasileiros, o que chamou bastante atenção com relação a este item foi que os bibliotecários que atuam nas bibliotecas especializadas sejam estas: médicas, jurídicas, economia etc., em sua grande maioria, adquiriam suas competências informacionais e domínio sobre as bases de dados especializadas na prática, ou por iniciativas particulares de realizarem cursos de aperfeiçoamento.

Dentro desta ótica, os bibliotecários, uma vez que desempenham sua atividade em uma determinada área do conhecimento, passam a ser parte inerente desse campo do conhecimento, o que, certa forma, torna o bibliotecário especializado, de forma que suas particularidades precisam adequar-se para prestar seus serviços de uma melhor maneira.

Analisando os avanços das TIC, percebeu-se que a internet, que hospeda uma grande massa da produção de informação técnico-cientifica na área médica, pode, evidentemente, contribuir para a tomada de decisão de um médico. Por outro lado, a internet que contém milhares de informações não confiáveis, só reforça grandemente a necessidade da interação entre médicos e os bibliotecários no sentido de localizar, avaliar e usar efetivamente as informações relevantes.

Neste processo de localizar, avaliar e usar efetivamente as informações, pode-se perceber, resgatando o estudo de Schacher (2001), Cañedo Andalia (2002) e Crestana (2003), relatam que a falta de tempo dos médicos em capacitar-se com competências informacionais na busca das melhores informações, abriu-se um espaço sólido para atuação do bibliotecário como intermediador entre a informação e os médicos. 
Pode-se perceber que a falta de conhecimento das fontes mais atualizadas e de credibilidade, e saber tirar destas fontes as suas melhores informações, por parte dos médicos, foi um grande passo dos bibliotecários para ganhar reconhecimento entre os médicos, além do público em geral, situação na qual o bibliotecário pode interagir oferecendo informações corretas sobre uma determinada doença.

Face a esta questão, foi observado que os bibliotecários necessitam reconhecer os territórios “férteis e promissores” na área médica, mas, para que isso ocorra, é necessário que os mesmos busquem competências, além dos já adquiridos em sua formação acadêmica.

Entendemos também que as pesquisas apresentadas na revisão evidenciaram que formação genérica dos bibliotecários brasileiros, ou seja, ampla e não rígida, de certa forma, capacitam estes profissionais em aturem nas bibliotecas médicas, entretanto, ainda à necessidade da adequação destes profissionais com as competências especificas.

Foi possível observar na literatura que os bibliotecários médicos tem a missão de facilitar o acesso à informação que possui relevância, advinda de pesquisas cientificas. Foram identificadas as principais competências (habilidades e atitudes) dos bibliotecários médicos como:

- aptidão com área médica: esta característica gera maior motivação para pesquisa em informação em saúde;

- pró-atividade: lidar com diferentes situações que podem ser apresentadas na comunidade médica;

- saber criar estratégias de buscas: a busca deve se ater à questão primordial, estabelecida na formulação do problema, além de superar o perfil dos bibliotecários convencionais, acostumados a responderem às questões que já estejam formuladas;

- excelência na comunicação oral e escrita

- aptidão para o ensino: deve saber transmitir seus conhecimentos aos profissionais da saúde, que, muitas vezes, desconhecem os recursos informacionais de sua área de conhecimento; 
- conhecer o cenário médico em que está envolvido: o bibliotecário médico deve reconhecer as terminologias médicas, assim como as fontes de informação em saúde que visa qualificar o atendimento.

Caracteristicamente, os bibliotecários médicos auxiliam os profissionais da área da saúde, ajudando-os na busca de casos semelhantes ao problema do paciente, buscando fontes de pesquisa que auxiliam o diagnóstico do médico, as pesquisas acadêmicas dos discentes de Medicina, e leva informação sobre saúde às pessoas através de diferentes canais de comunicação, tais como portais na internet e o acervo de unidades de informação.

Após análise da formação e das competências informacionais dos bibliotecários médicos no Brasil, é possível relacionar as habilidades dos bibliotecários médicos de diferentes contextos, trazendo ao perfil deste profissional maior dinamismo, tornando-os mais especializados na área médica.

Quanto às competências dos bibliotecários médicos, frente suas atividades desenvolvidas nas bibliotecas médicas, optou-se em destacar a relação entre as principais competências informacionais dos bibliotecários médicos norte-americanos, apresentado pela Medical Library Association (1992), com as competências informacionais dos profissionais que atuam nas bibliotecas médicas no Brasil, discutidas por Pinto (2005) e Pereira (2005).

Para análise, aglutinaram-se as principais competências informacionais dos bibliotecários médicos de diferentes contextos, visando comparar os níveis de habilidades e atitudes predominantes desta prática biblioteconômica, no sentido de verificar se as competências informacionais têm sido direcionadas em promover o desenvolvimento destes profisssionais da informação.

Em termos comparativos, vale ater-se as várias disposições das competências informacionais, uma vez que se pretende apresentar a relação significante entre formação e a competência informacional, ou seja, entre conhecimento e a efetiva utilização desse conhecimento na prática da Biblioteconomia Médica. 


\begin{tabular}{|l|l|}
\hline \multicolumn{1}{|c|}{$\begin{array}{c}\text { Principais competências inseridas nos } \\
\text { bibliotecários-médicos dos EUA, segundo } \\
\text { Medical Library Association (1992): }\end{array}$} & $\begin{array}{c}\text { Principais Competências presentes nos } \\
\text { bibliotecários-médicos brasileiros, segundo Pinto } \\
\text { (2005) e Pereira (2005): }\end{array}$ \\
\hline$>\begin{array}{l}\text { Conhecer o cenário médico em que } \\
\text { está envolvido e as terminologias }\end{array}$ & $>\begin{array}{l}\text { Familiaridade com tecnologias da } \\
\text { informação; }\end{array}$ \\
$\begin{array}{l}\text { comuns à área médica; } \\
\text { Conhecer os serviços e as fontes de } \\
\text { informação em saúde; }\end{array}$ & $>\begin{array}{l}\text { Destreza na realização de busca de } \\
\text { informações em saúde; } \\
>\text { Gestão da informação; }\end{array}$ \\
$\begin{array}{l}\text { Habilidades com as estratégias de } \\
\text { buscas. }\end{array}$ & $\begin{array}{l}\text { Capacidade de manter bom } \\
\text { relacionamento com os usuários. }\end{array}$ \\
\hline
\end{tabular}

Quadro 1 - Relação das competências dos bibliotecários-médicos MLA x Pinto (2005) e Pereira (2005)

Observa-se que em ambos estudos no quadro 1, apresenta-se uma relação de complementação entre as competências informacionais, em que os bibliotecários médicos devem possuir a capacidade de formular estratégias de buscas, ou seja, ter habilidades e destreza para realizar recuperar informações com qualidade e relevância.

Isso mostra que, os bibliotecários médicos concentram uma parte significativa de suas competências informacionais baseada no perfil dos bibliotecários genérico que, também devem ser capazes de formular estratégias de buscas, mas, com a diferença de não adquirirem conhecimentos específico de uma área do conhecimento, como demanda aos bibliotecários que atuam nas bibliotecas médicas.

Também pode ser observada, a familiaridade com as tecnologias da informação e as fontes de informação em saúde, que estão disponíveis no ambiente da internet, são de suma relevância para bibliotecários médicos, que devem, no exercício de suas atividades, ter domínio das TIC visando prestar melhor qualidade nos serviços recuperação e disseminação de informação aos seus usuários.

Portanto, para que se pudesse verificar a proposta da formação dos profissionais da informação em saúde do curso de Ciência da Informação da USP de Ribeirão Preto, recorreu-se em comparar às disciplinas do curso mencionado, com as competências informacionais apresentadas pela MLA (1992), de forma a observar as características que envolvem os profissionais que atuam nas bibliotecas médicas. 


\begin{tabular}{|c|c|}
\hline $\begin{array}{l}\text { Disciplinas para formação de profissionais } \\
\text { da informação em saúde (Galvão e Leite, } \\
\text { 2009): } \\
\end{array}$ & $\begin{array}{c}\text { Competências informacionais dos bibliotecários- } \\
\text { médicos dos EUA, segundo Medical Library } \\
\text { Association (1992): }\end{array}$ \\
\hline $\begin{array}{l}\text { Análise, avaliação e leitura; } \\
\text { Documentária em saúde; } \\
\text { > Comunicação e difusão de } \\
\text { conhecimentos em saúde; } \\
\text { > Documentação em saúde; } \\
\text { > Fontes de informação em saúde; } \\
\text { > Gestão de serviços de saúde e } \\
\text { sistemas de informação; } \\
\text { > Noções básicas em saúde; } \\
\text { > Noções de epidemiologia. }\end{array}$ & $\begin{aligned} &> \text { Compreensão da ciência da saúde, bem como } \\
& \text { das políticas da saúde vigentes, problemas e } \\
& \text { tendências que impactam o ambiente da } \\
& \text { biblioteca médica; } \\
&>\text { Compreender a liderança, finanças, } \\
& \text { comunicação e técnicas de gestão; } \\
&>\text { Compreender os princípios e práticas } \\
& \text { relacionadas com o fornecimento de serviços de } \\
& \text { informação que satisfaçam as necessidades dos } \\
& \text { usuários; } \\
&>\text { Ter a capacidade para gerenciar a informação } \\
& \text { sobre saúde; } \\
&>\text { Compreender e utilizar tecnologias e sistemas } \\
& \text { para gerenciar todas as formas de informações; } \\
&>\text { Entender o quadro curricular de seus usuários e } \\
& \text { ter a capacidade de ensinar; } \\
&>\text { As formas de acesso, organização e utilização } \\
& \text { de informações; } \\
&>\text { Compreender os métodos de investigação } \\
& \text { científica, ter a capacidade de analisar e filtrar } \\
& \text { literatura pesquisada em bases de dados. }\end{aligned}$ \\
\hline
\end{tabular}

Quadro 2 - Tópicos da formação e das competências informacionais dos bibliotecários-médicos

Em ambos os casos, observa-se que o domínio das fontes de informação em saúde, gestão da informação, são habilidades fundamentais no perfil dos bibliotecários médicos, uma vez que este tem, entre as suas atividades, auxiliar os médicos a localizarem as melhores informações.

O que nos chamou atenção também foi que, comparando as disciplinas propostas pelo curso mencionado com as competências informacionais expostas pela MLA (1992), as fontes e gestão da informação em saúde sobrepõem, na análise comparativa, com as demais atividades que envolvem o bibliotecário médico.

Entretanto, é importante ressaltar que a comparação demonstrada direciona as habilidades que os bibliotecários que atuam nas bibliotecas médicas precisam noções básicas em saúde e epidemiologia, podem agregar valor na questão da compreensão da ciência da saúde, exposto pela MLA (1992), uma vez que não é delimitado em qual compreensão se 
deve ter em relação da ciência da saúde. Entretanto, pode ser observado que compreensão das políticas de saúde, se relaciona com as noções básicas em saúde.

A análise da literatura levantada indicou que os estudos que buscam clarificar a prática da Biblioteconomia Médica para os bibliotecários brasileiros devem ser intensificados no sentido de alcancem melhores competências para a atuação do bibliotecário-médico.

\section{Considerações finais}

Ao analisar os conceitos da Biblioteconomia Médica, constatou-se que se trata de uma área de atuação dos bibliotecários que tem como objetivo suprir as necessidades informacionais dos médicos, docentes, discentes da área médica e o público em geral através do domínio das fontes de informação em saúde, como também das estratégias de buscas eficazes na literatura médica. Entretanto, o grande diferencial dos bibliotecários médicos reside no fato dos mesmos poderem prestar apoio à tomada de decisão médica, utilizando para isto os fundamentos da MBE.

Quanto às competências informacionais tidas como necessárias para os bibliotecários médicos brasileiros, observou-se que são poucas específicas no que tange à literatura referenciada, a respeito ao domínio bases de dados especializadas, estratégias de buscas e das terminologias da área médica. Isto evidencia a necessidade de esforços por parte da formação acadêmica em subsidiar os bibliotecários generalistas a estarem aptos com competências para atuarem com serviços de informação mais especializados.

Vários fatores já alertavam para as necessidades de estudos sobre as competências informacionais dos bibliotecários brasileiros relacionados às atividades desempenhadas por este profissional. Dentre esses fatores, podem ser citados: melhoria de qualidade dos serviços, acesso à informação, do controle, organização, disseminação da informação e na educação dos usuários para ser competente em informação.

Pode-se afirmar que as competências informacionais dos bibliotecários estão relacionadas com sua formação, pois, considerando que o ambiente e os serviços informacionais alteram-se constantemente com evolução das TIC, a formação generalista dos bibliotecários brasileiros possibilita que os mesmos não percam os parâmetros das

(C) Revista Digital de Biblioteconomia e Ciência da Informação,Campinas, v.7, n. 2, p. 199-218, jan./jun. 2010- ISSN: 1678-765X. 
competências necessárias para realizarem os serviços que demandam as atividades de uma biblioteca especializada, haja vista que a educação continuada é de suma importância para atualização e aperfeiçoamento deste profissional.

É relevante considerar que as competências informacionais também podem ser adquiridas pelos bibliotecários na prática, ou seja, nas ações no trabalho diário, entretanto, conforme já anunciado, educação continuada deve ser encarada com uma atividade na rotina dos bibliotecários.

Ficou claro que os bibliotecários generalistas possuem através de sua formação, as competências informacionais necessárias para atuarem junto às bibliotecas médicas, partir da proposta de competência informacional estabelecida pelo Parecer CNE/CES no. 492/2001 (BRASIL, 2001). Entretanto, espera-se que os bibliotecários médicos aperfeiçoem constantemente os seus conhecimentos em tecnologias e fontes de informação em saúde que darão suporte à gestão de informação requerida pelas bibliotecas médicas.

No Brasil, a Biblioteconomia Médica aparece como uma prática promissora. Dessa maneira, espera-se que este trabalho possa contribuir como uma referência teórica e bibliográfica, abrindo novas discussões na área de Ciência da Informação sobre a descrição de competências informacionais dos bibliotecários que atuam na área médica.

\section{Referências}

ALMEIDA JR., O. F. Profissional da informação: entre o espírito e a produção. In: VALENTIM, M. L. P. et al (Org.). Profissionais da informação: formação, perfil e atuação profissional. São Paulo: Polis, 2002.

AMERICAN LIBRARY ASSOCIATION (ALA). Characteristics of programs of information literacy that illustrate best practices: a guideline. ALA, 2003. Disponível em: <http://www.ala.org/ala/acrl/acrlstandards/characteristics.htm>. Acesso em: 15 maio 2008.

ANNAN G. L. The Medical Library Association in retrospect, 1937-1967. Bulletin of the Medical Library Association, Chicago, v.86, n.2, 270-8, Apr. 1998. Disponível em: $<$ http://www. pubmedcentral. nih.gov/articlerender. fcgi?artid=226366>. Acesso em: 11 fev. 2009. 
ASSOCIAÇÃO BRASILEIRA DE EDUCAÇÃO EM CIÊNCIA DA INFORMAÇÃO (ABECIN). Proposta de diretrizes curriculares para os cursos de Biblioteconomia. Londrina: ABECIN, 2000. Disponível em: <http://www.abecin.org/Textos/DiretrizesCI MecVersao2.rtf $>$. Acesso em: 27 fev. 2009.

ATALLAH, A.; CASTRO, A. Evidências para melhores decisões clínicas. São Paulo: UNIFESP, 1998. Disponível em: <http://www. epm.br/ cochrane/ bestevidence.htm>. Acesso em: 01 agosto 2008.

BELL, J. A. H. History of the Medical Library Association's credentialing program. Bulletin of the Medical Library Association, Chicago, v.84, n.3, p.320-33, July 1996. Disponível em: <http://www. pubmedcentral.nih.gov/ articlerender.fcgi? artid=226152>. Acesso em: 20 jan. 2009.

BELLUZZO, R.C.B. A information literacy como competência necessária à fluência científica e tecnológica na Sociedade da Informação: uma questão de educação. In: SIMPÓSIO DE ENGENHARIA DE PRODUÇÃO DA UNESP, 7., 2001, Bauru. Anais eletrônicos... Bauru: UNESP, 2001. Disponível em:

<http://www.simpep.feb.unesp.br/anais8/ana8c.html\#GI>. Acesso em: 28 abr. 2008.

BRASIL. Conselho de Ensino Superior. Parecer CNE/ CES N 492/ 2001: Diretrizes Curriculares para os Cursos De biblioteconomia. Disponível em: <http//:www.mec.gov.br/cne/pdf/ces0492.pdf>. Acesso em: 25 fev. 2009.

CAMPELO, B. O movimento da competência informacional: uma perspectiva para o letramento informacional. Ciência da informação, Brasília, v. 32, n. 3, p. 28-37, set./dez. 2003. Disponível em: <http://www.eci.ufmg.br/bogliolo/downloads/ CAMPELO\%20Competencia\%20Informacional.pdf>. Acesso em: 15 set. 2008.

CAMPELO, B,; ABREU, V. L. F. G. Competência informacional e a formação do bibliotecário. Perspectiva em Ciência da Informação, Belo Horizonte, v.10, n.2, p.178193, jun. 2005. Disponível em: <http:// www.eci. ufmg.br/pcionline/index.php/pci/ article/viewFile/2/150>. Acesso em: 15 set. 2008.

CAÑEDO ANDALIA, R. Del bibliotecario clínico al informacionista: de la gerencia de información a la gestión del conocimiento. ACIMED; v.10, n.3, mayo-jun. 2002.

Disponível em: <http://scielo.sld.cu/scielo.php?script=sci_arttext\&pid=S1024- 94352002 000300006\&lng=pt\&nrm=iso\&tlng=es >. Acesso em: 10 ago. 2008.

CAREGNATO, S. E. O desenvolvimento de habilidades informacionais: o papel das bibliotecas universitárias no contexto da informação digital em rede. Revista de Biblioteconomia \& Comum, Porto Alegre, v. 8, p. 47-55, 2000.

CRESTANA, M. F. Bibliotecários da área médica: o discurso a respeito da profissão.

Perspectiva em Ciência da Informação, Belo Horizonte, v. 8, n. 2, p. 134-149, jul./dez. 2003. Disponível em: <http://www.eci.ufmg.br/pcionline/ index.php/pci/article/view/365/ 183>. Acesso em: 19 fev. 2009.

DUDZIAK, E. A. Information literacy: princípios, filosofia e prática. Ciência da Informação, Brasília, v.32, n.1, p. 23-35. 2003. Disponível em: $<$ http://www.ibict.br/cionlinr>. Acesso em: 25 mar. 2008.

(c) Revista Digital de Biblioteconomia e Ciência da Informação,Campinas, v.7, n. 2, p. 199-218, jan./jun. 2010- ISSN: 1678-765X. 
FERREIRA, D. T. Profissional da informação: perfil de habilidades de demandas pelo mercado de trabalho. Ciência da Informação, Brasília, DF, v.32, n.1, p.42-9, 2003. Disponível em: <http://www.scielo.br/pdf/ci/v32n1/15972.pdf > . Acesso em: $17 \mathrm{fev}$. 2008.

GALVÃO, M.C.B.; LEITE, R.A.F. Do bibliotecário médico ao informacionista: traços semânticos de seus perfis e competências. Transinformação, Campinas, v.20, n.2, p.181-91, maio/ago.2008. Disponível em: <http://revistas.puc-

campinas.edu.br/transinfo/viewarticle.php?id=198>. Acesso em: 12 fev. 2009.

HATSCHBACH, M. H. L. Information literacy: aspectos conceituais e iniciativas em ambientes digitais para estudantes de nível superior. 2002. 104f. Dissertação (Mestrado em Ciência da Informação) - Universidade Federal do Rio de Janeiro - UFRJ/IBICT, Rio de Janeiro, 2002.

KAJBERG, L; LORRING, L. European curriculum reflection on library and information science. Copenhagen: the royal school of library and informatiom science, 2005. disponivel em: <http://biblis.db.dk/Archimages/423.12.05.PDF>. Acesso em: 17 mar. 2009.

KRAMER, G. (Comp.). La Profisión bibliotecaria. In: KRAMER, G. Notas bibliotecológicas. 2. ed. Callejon de San Antonio: Pax-México; Libraria Carlos césarman, 1972. p. 159-89.

MARTINEZ-SILVEIRA, M. S. A informação cientifica na prática médica: estudo do comportamento informacional do médico residente. 2005. 184 f. Mestrado (Ciência da Informação) Universidade Federal da Bahia. Salvador.

MEDICAL LIBRARY ASSOCIATION. Platform for change: the educational policy statement of the Medical Library Association. Chicago: The Association, 1992. Disponível em: <http://www.mlanet.org/education/platform/> Acesso em: 05 março 2009.

NAKAYAMA, E.H. A biblioteca científica e o processo de busca de informação por pacientes. São Paulo, 102f. Mestrado Profissional (Ensino em Ciências da Saúde) Escola Paulista de Medicina, Universidade Federal de São Paulo. São Paulo, 2004.

ORTEGA Y GASSET, J. History as system. New York: Norton, 1935.

PEREIRA, E.A.J. O perfil do bibliotecário da área de ciência da saúde em Santa Catarina. 2005. 121 f. Dissertação (Mestrado em Ciência da Informação) - Universidade Federal de Santa Catarina, Santa Catarina, 2005.

PINTO, R. R. O profissional da informação em ciências da saúde: subsídio para desenvolvimento de cursos de capacitação no Brasil. 2005, 130f. Dissertação (Mestrado Profissional Ensino em Ciências da Saúde) - Escola Paulista de Medicina, Universidade Federal de São Paulo, São Paulo, 2005.

ROSENBERG, W.; DONALD, A. Evidence based medicine; na approach to clinical problem-solving. BWJ medical publication of the year, v.310, p.1122-6, 1995. 
Disponível em: <http://www.bmj.com/cgi/content/full/310/6987/1122> Acesso em: 22 fev. 2009

SCHACHER, L. F. Clínical librarianship: its value in medical care. Electronic Journal of Academic and Special Librarianship, v.134, n. 8, p. 717-20, 2001. Disponível em: $<$ http://southernlibrarianship.icaap.org/content/v05n02/lappa_e01.htm>. Acesso em: 18 abr. 2008.

VALENTIM, M.L. Formação: competências e habilidades do profissional da informação. In: VALENTIM, M.L. Formação do profissional da informação. São Paulo: Polis, cap.6, p. 117-48. 2002.

\section{Alexander Willian Azevedo}

Bacharelado em Ciência da Informação com Habilitação em Biblioteconomia pela PUC-Campinas. Mestre em Ciência da Informação pelo Programa de Pós Graduação em Ciência da Informação, Centro de Ciências Humanas e Sociais Aplicadas, Pontifícia Universidade Católica de Campinas I PUC-Campinas. aw.azevedo@yahoo.com.br

\section{Vera Silvia Marão Beraquet}

Graduação em Biblioteconomia pela Pontifícia Universidade Católica de Campinas, mestrado em Biblioteconomia pela Loughborough University e doutorado em Biblioteconomia também pela Loughborough University. braquet@puc-campinas.edu.br

Recebido em: 30/06/2009

Aceito para publicação em: jul/2009 